\title{
Gastroduodenal mucosa in uraemia: endoscopic and histological correlation and prevalence of helicobacter-like organisms
}

\author{
A Wee, J Y Kang, M S Ho, H L Choong, A Y T Wu, I H Sutherland
}

\begin{abstract}
This study aimed to determine the prevalence of endoscopic and histological gastroduodenitis as well as helicobacter-like organisms in patients with end stage renal failure undergoing maintenance dialysis treatment. A total of 322 out of 422 patients in our dialysis programme underwent endoscopy and gastroduodenal biopsy specimens were taken from 260. Endoscopic gastroduodenitis occurred in 158 (49\%). Histological gastritis occurred in the gastric body or antrum in 134 patients $(52 \%)$ and duodenitis in $52(21 \%)$. There was no correlation between endoscopic and histological gastritis in contrast to a significant correlation for duodenitis. Helicobacter-like organisms occurred in the body or antrum in 81 (31\%). Their presence was associated with gastritis - in particular acute and acute on chronic gastritis rather than chronic gastritis. Patients with gastritis were significantly older than those without $(p<0.001)$ and had lower basal and peak acid outputs.
\end{abstract}

Although we now know that uraemic patients on maintenance dialysis treatment are not especially prone to develop peptic ulcer, ${ }^{1-5}$ the frequency of complicated ulcer disease does seem to be increased after kidney transplantation. ${ }^{67} \mathrm{Helico}-$ bacter pylori is associated with both peptic ulcer and gastritis, and a causal role has been postulated for the bacterium in both conditions. ${ }^{8-11}$ The prevalence of gastritis and gastric helicobacter in uraemia is therefore of interest. Although gastroduodenitis has been studied in several series of uraemic patients, ${ }^{1-3}{ }^{12-16}$ the prevalence of gastric helicobacter in uraemia has not, to our knowledge, been reported before. We therefore investigated the relation between histological gastroduodenitis and helicobacter-like organisms in a large series of patients with end stage renal failure undergoing maintenance dialysis treatment.

\section{Methods}

\section{PATIENT SELECTION}

From May 1984 to July 1988 all patients with end stage renal failure undergoing maintenance haemodialysis or peritoneal dialysis at the
Department of Renal Medicine, Singapore General Hospital, were requested to undergo routine gastroduodenoscopy as part of their pretransplant evaluation. The definition of end stage renal failure used was a serum creatinine concentration $>884 \mu \mathrm{mol} / \mathrm{l}$, a creatinine clearance rate of $<5 \dot{\mathrm{m} l} / \mathrm{minute}$, or both.

Endoscopic findings in the first 114 patients of this series have previously been reported in an assessment of peptic ulcer prevalence in uraemia.

CLINICAL AND ENDOSCOPIC ASSESSMENT

Informed consent was obtained from each patient. They were questioned about current or previous upper abdominal pain and use of tobacco, alcohol, and analgesics. All endoscopies (except for four) were performed by one endoscopist (JYK) under local anaesthesia and using the Olympus GIFQ or Q10 gastroscope. Endoscopic gastritis or duodenitis was said to be present if erythema, petechiae, or erosions or all three were present in the gastric body, gastric antrum, or the duodenal bulb.

\section{HISTOLOGICAL ASSESSMENT}

After diagnostic endoscopy one biopsy specimen was taken from each of the following sites: greater curve mid-body; lesser curve midantrum, and duodenal bulb. All specimens were fixed in $10 \%$ buffered formalin and paraffin sections were stained with haematoxylin and eosin and the periodic acid-Schiff technique. Biopsy specimens were assessed without prior knowledge of endoscopic findings. Histological gastritis and duodenitis were defined by a modification of the system used by McNulty et al. ${ }^{17}$ Mononuclear and polymorphonuclear cellular infiltration were each graded from zero to four. The following criteria were used for mononuclear cell grading:

Grade 0 - absence of mononuclear cells in the lamina propria;

Grade 1 - occasional cells;

Grade 2 - small number of cells;

Grade 3-moderate number of cells;

Grade 4- large number of cells.

The following criteria were used for grading of polymorphonuclear cells:

Grade 0-absence of polymorphonuclear cells; 
Grade 1 - occasional cells in the lamina propria;

Grade 2 - small number of cells in the lamina propria with or without occasional intraepithelial polymorphonuclear cells;

Grade 3 - moderate number of cells in the lamina propria and intraepithelial cells;

Grade 4-large number of cells in the lamina propria and intraepithelial and intraluminal polymorphonuclear cells.

If the acute inflammatory score was 1 or more, or the chronic inflammatory score was 3 or more, gastritis or duodenitis was said to be present. Gastritis or duodenitis was said to be acute if the polymorphonuclear cellular score was 1 or more with a mononuclear cellular score of under 3 . Chronic gastritis or duodenitis was diagnosed if the mononuclear cellular score was 3 or above while the acute inflammatory score was 0 . Acute on chronic inflammation was diagnosed when the acute and chronic inflammatory scores were greater than 0 and 2 respectively. The occurrence of atrophic gastritis and intestinal or gastric metaplasia was separately recorded. The presence or absence of helicobacter-like organisms was assessed using the haematoxylin and eosin stain.

A blinded review of 49 biopsy specimens ( 24 antral and 25 gastric body) by the same pathologist showed agreement in helicobacter-like organisms and acute and chronic inflammatory scores in 49 of $49(100 \%), 43$ of $49(88 \%)$, and 41 of 49 subjects $(84 \%)$ respectively. In all but one instance in which intraobserver variation occurred for inflammatory scores, the differences were single grade. Another blinded comparison of serial sections of 126 consecutive antral biopsy specimens stained with haematoxylin and eosin and with Giemsa ${ }^{18}$ showed agreement in helicobacter-like organism scores in 123 (98\%). Because bacterial culture was not performed in this study, the term helicobacter-like organism rather than $H$ pylori is used.

\section{STATISTICAL ANALYSIS}

Categorical data were assessed by the $\chi^{2}$ and Fisher's exact tests. Numerical data were assessed by the Wilcoxon rank sum test. Probability values of $<0.05$ were considered significant.

\section{Results}

\section{PATIENT POPULATION}

From 1 May 1984 to 30 June 1988, 422 patients were accepted for chronic dialysis treatment 278 for haemodialysis and 144 for peritoneal dialysis. Fifty two patients (all but one on peritoneal dialysis) were over the age of 50 years and as they were not being considered for transplantation, they did not undergo endoscopy. Forty eight patients ( 39 on haemodialysis, nine on peritoneal dialysis) were also not included in the study for the following reasons: recently endoscoped elsewhere (17), refused (11), left the country (4), died (2), unable to tolerate endoscopy (1), oesophageal stricture (1), endoscopy records mislaid (1), previous duodenal ulcer surgery (1), other reasons (10).
There were therefore 322 patients in the study - 238 on haemodialysis and 84 on peritoneal dialysis. Biopsy specimens were not part of the protocol in the early part of the study and for a four month period in 1986 a temporary change in the charging system precluded biopsy specimens from being taken. Gastric biopsy specimens were therefore not obtained from 62 patients. Various biopsy specimens were unsatisfactory in the following numbers of cases: body (11), antral (8), duodenal cap (13). The numbers of biopsy specimens available for study were therefore: body 249, antral 252, duodenal cap 247 .

\section{CLINICAL FEATURES}

One hundred and eighty seven subjects were men and 135 were women. Two hundred and seventy nine patients were Chinese, 31 were Malays, 11 were Indians, and one was an Arab. Two hundred and thirty eight patients were on haemodialysis and 84 on peritoneal dialysis. Patients on haemodialysis had a median age of 37 years (range 18-56) compared with 38 years (range 13-63) for those on peritoneal dialysis. The causes of renal failure as judged by clinical or radiological criteria, or both, were: chronic glomerulonephritis (187), chronic pyelonephritis (10), diabetes mellitus (6), systemic lupus erythematosus (4), Henoch-Schonlein nephritis (4), polycystic kidneys (3), reflux nephropathy (2), tuberculosis (1), calculous disease (1), and unknown (104). Thirty seven patients (11\%) were smokers, 19 patients $(6 \%)$ were drinkers, while none admitted to regular analgesic intake (more than once a month). Sixty five patients (20\%) admitted to dyspepsia.

\section{ENDOSCOPIC FINDINGS}

Only two patients had peptic ulcers: one a corpus gastric ulcer and one duodenal ulcer. Erythema was present in the gastric body in six patients $(2 \%)$, petechiae in 22 patients $(7 \%)$, and erosions in one patient $(0.3 \%)$. Two hundred and ninety four patients $(91 \%)$ had normal gastric body mucosa. In the gastric antrum, erythema occurred in 46 patients $(14 \%)$, petechiae in 61 patients $(19 \%)$, and erosions in 40 patients $(12 \%)$. The antral mucosa was normal in 199 patients (62\%). The whole stomach was endoscopically normal in 182 patients $(57 \%)$

Erythema was detected in the duodenal cap in 28 patients $(9 \%)$, petechiae in three patients $(1 \%)$, and erosions in 23 patients $(7 \%)$. The duodenal mucosa was endoscopically normal in 272 patients $(84 \%)$. One hundred and sixty four patients (51\%) had totally normal stomachs and duodenal caps on endoscopy.

\section{HISTOLOGICAL FINDINGS (TABLE I)}

Gastritis was present in body mucosa in 93 patients $(37 \%)$. This was diagnosed as chronic in 23 patients $(25 \%)$, acute on chronic in 45 patients $(48 \%)$, and acute in $25(27 \%)$. Gastritis was diagnosed in antral biopsy specimens in 113 patients (45\%): of these, $15(13 \%)$ showed acute gastritis, $20(18 \%)$ chronic gastritis, while the gastritis was shown to be acute on chronic in 78 
TABLE I Gastroduodenitis and helicobacter-like organisms (HLO) in uraemia

\begin{tabular}{|c|c|c|c|c|c|}
\hline & \multirow[b]{2}{*}{$\begin{array}{l}\text { Normal } \\
\text { mucosa }\end{array}$} & \multicolumn{4}{|c|}{ Inflamed mucosa } \\
\hline & & All & Acute & $\begin{array}{l}\text { Acute on } \\
\text { chronic }\end{array}$ & Chronic \\
\hline \multicolumn{6}{|l|}{ Body: } \\
\hline No & 156 & 93 & 25 & 45 & 23 \\
\hline $\begin{array}{l}\text { No (\%) with HLO } \\
\text { Antrum: }\end{array}$ & $10(6)^{\star}$ & $62(67)^{\star}$ & $18(72)\}$ & $36(80) \|$ & $8(35) \S \|$ \\
\hline \multirow{3}{*}{$\begin{array}{l}\text { Antrum: } \\
\text { No } \\
\text { No (\%) with HLO } \\
\text { Duodenum: } \\
\text { No } \\
\text { No (\%) with HLO }\end{array}$} & $\begin{array}{l}139 \\
4(3) \dagger\end{array}$ & ${ }_{69}^{113}(61) \dagger$ & $\begin{array}{l}15 \\
6(40) 9\end{array}$ & $\begin{array}{l}78 \\
59(76) \llbracket \star \star\end{array}$ & $\begin{array}{l}20 \\
4(20)^{\star \star}\end{array}$ \\
\hline & & & & & \\
\hline & $\begin{array}{l}195 \\
0 \neq\end{array}$ & $\begin{array}{l}52 \\
3(6) \ddagger\end{array}$ & $\begin{array}{l}28 \\
1(4)\end{array}$ & $\begin{array}{l}10 \\
1(10)\end{array}$ & 14 \\
\hline
\end{tabular}

patients (69\%). Gastritis was present in either the gastric body or antral mucosa in 134 patients (53\%). Atrophic changes were present in body mucosa in 31 patients $(12 \%)$ and intestinal metaplasia in one patient $(0 \cdot 4 \%)$. Corresponding figures for antral mucosa were $87(35 \%)$ and 22 (9\%) respectively.

Duodenitis occurred in 52 patients $(21 \%)$. It was acute in 28 (54\%), chronic in $14(27 \%)$, and acute on chronic in $10(19 \%)$. Atrophic changes had occurred in three biopsy specimens (1\%) and gastric metaplasia in six (2\%). Helicobacter-like organisms were identified in gastric body mucosa in 72 patients $(29 \%)$, in antral mucosa in 73 patients $(29 \%)$, in body or antral mucosa in 81 patients $(31 \%)$, and in duodenal cap mucosa in three patients $(1 \%)$. In all the patients in whom helicobacter-like organisms occurred in the duodenal cap, gastric metaplasia was present. There was agreement between the presence of helicobacter-like organisms in the body and of the antrum in 222 of 243 specimens (91\%).

The occurrence of helicobacter-like organisms was associated with the occurrence of histological gastritis in both body and antral mucosa. This

TABLE II Endoscopic and histological correlation of the gastric mucosa in uraemia

\begin{tabular}{llc}
\hline & \multicolumn{2}{l}{ Endoscopic gastroduodenitis } \\
\cline { 2 - 3 } & Present & Absent \\
\hline Body: & 1 & 92 \\
Histological gastritis & 19 & $137^{\star}$ \\
No gastritis & 36 & 77 \\
Antrum: & 64 & $75^{\star}$ \\
Histological gastritis & 17 & 35 \\
No gastritis & 17 & $178 \dagger$ \\
Duodenal cap: & Histological duodenitis & \\
No duodenitis &
\end{tabular}

${ }^{\star} \mathrm{p}<0.05$ (negative correlation). $+\mathrm{p}<0.001$

TABLE III Comparison between uraemic patients with and without histological gastritis

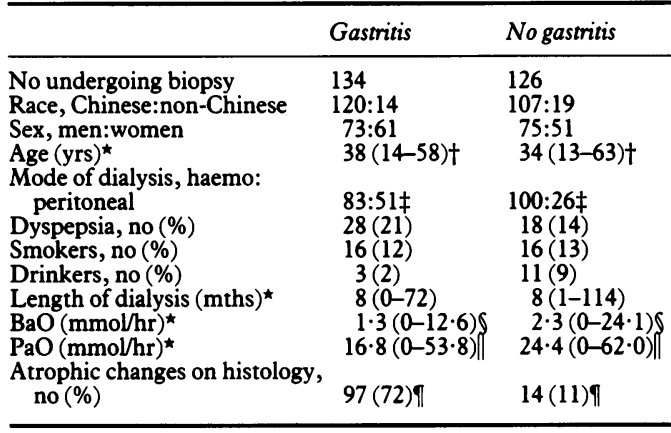

${ }^{\star}$ Median (range); $\{\mathrm{p}<0.001 ; \dagger \ddagger \| \mathrm{p}<0.01 ;$ \$p $<0.05$ $\mathrm{BaO}=$ basal acid output; $\mathrm{PaO}=$ peak acid output. correlation was stronger with acute and acute on chronic gastritis than with chronic gastritis.

\section{ENDOSCOPIC/HISTOLOGICAL CORRELATIONS}

(TABLE II)

There was no correlation between endoscopic and histological gastritis. This lack of correlation also applied to individual features of endoscopic gastritis as earlier defined. Endoscopic duodenitis, in contrast, correlated well with histological changes.

\section{NODULAR DUODENITIS AND BRUNNER'S GLAND} HYPERPLASIA

A nodular appearance of the duodenal cap was seen in six patients. Brunner's gland hyperplasia was found in one of these on biopsy and gastric metaplasia in four. Brunner's gland hyperplasia was also found in biopsy specimens of endoscopically normal duodenal mucosa in 26 patients (11\%).

\section{CHARACTERISTICS OF PATIENTS WITH}

HISTOLOGICAL GASTRITIS (TABLE III)

Patients with gastritis were significantly older than those without $(\mathrm{p}<0.001)$ but there was no difference in sex or race distribution, cause of renal failure, frequency of dyspepsia, or use of tobacco and alcohol. Patients with gastritis were more likely to show atrophic features in their gastric histology and had lower basal and peak acid outputs when compared with subjects without gastritis. Patients on peritoneal dialysis were more likely to have gastritis when compared with those on haemodialysis. The two groups were comparable in age and frequency of helicobacterlike organisms, and the reason for the different prevalences of gastritis was therefore unclear.

\section{Discussion}

Our concepts on the pathogenesis of histological gastritis have changed since the clarification of its relation with $H$ pylori. ${ }^{8-11}$ Epidemiological studies showing a high prevalence of gastritis in apparently asymptomatic subjects, especially elderly ones, suggested that gastritis may be part of the normal process of aging. ${ }^{19-21}$ It is now thought, however, that type B gastritis unassociated with duodenogastric reflux is usually a consequence of infection with $H$ pylori. ${ }^{8-10}$ Increasing prevalences of gastritis with age probably reflected higher frequencies of infection with this organism. ${ }^{22}$

The prevalence of gastritis in our uraemic subjects was comparable with reports from other series of between 43 and $100 \% .^{1-13}{ }^{12-16}$ Helicobacter-like organisms occurred in $68 \%$ of biopsy specimens showing gastritis. This could be an underestimate since mucosal biopsy specimens were not cultured in our study. The frequency of dyspepsia, as elicited by routine questioning, was similar in uraemic patients with or without helicobacter-like organisms.

Forty nine per cent of our patients had gastroduodenitis at endoscopy. This is in line with reports from other centres in which endoscopic 
abnormalities occurred in $25-64 \%$ of uraemic patients on chronic dialysis treatment. ${ }^{1+623-25}$ Our finding that endoscopic and histological gastritis did not correlate but that endoscopic and histological duodenitis did, confirms findings by previous workers. ${ }^{26-28}$ The reason for this discrepancy is unclear.

Nodular duodenitis associated with Brunner's gland hyperplasia has been reported to be associated with uraemia. ${ }^{312} 132930$ We found that neither was common and the two features were not correlated.

In common with non-uraemic patients, our subjects with gastritis were older than those without. They also had lower gastric acid secretory capacities perhaps related to a higher frequency of glandular atrophy.

In conclusion, histological gastritis occurred in 134 of $260(52 \%)$ uraemic patients on maintenance dialysis treatment. Helicobacter-like organisms were found in $31 \%$ of our uraemic patients. It is possible that gastric helicobacter could be responsible for a high prevalence of peptic ulcer after transplantation but a prospective study is required to answer this question.

The authors would like to thank Dr C H Lim, head of the Department of Renal Medicine, for allowing them to study his Department of Renal Medicine, for allowing them to study his
patients, Dr K T Woo for encouragement, and Staff Nurse Molly patients, Dr K T Woo for encourag
Tan for organising the endoscopies.

1 Andriulli A, Malfi B, Recchia S, Ponti V, Triolo G, Segoloni $G$. Patients with chronic renal failure are not at a risk of G. Patients with chronic renal failure are not at a risk of
developing chronic peptic ulcers. Clin Nephrol 1985; 23: developing $245-8$.

2 Milito G, Taccone-Gallucci M, Brancaleone C, et al. The gastrointestinal tract in uremic patients on long-term haemodialysis. Kidney Int 1985; 28 (suppl 17): S157-60.

3 Franzin G, Musola R, Mencarelli R. Morphological changes of the gastroduodenal mucosa in regular dialysis uraemic patients. Histopathology 1982; 6: 429-37.

4 Margolis DM, Saylor JL, Geisse G, DeSchryver-Kecskemeti K, Harter HR, Zuckerman GR. Upper gastrointestinal disease in chronic renal failure. Arch Intern Med 1978; 38: $1214-70$.

5 Kang JY, Wu AYT, Sutherland IH, Vathsala A. Prevalence of peptic ulcer in patients undergoing maintenance hemodialysis. Dig Dis Sci 1988; 33: 774-8.

6 Musola R, Franzin G, Mora R, Marfrini C. Prevalence of gastroduodenal lesions in uremic patients undergoing dialysis and after renal transplantation. Gastrointest Endosc dialysis and after

7 Hadjiyannakis EJ, Evans JB, Smellie WAB, Calne RY. Gastrointestinal complications after renal transplantation. Lancet 1971; ii: 781-5.

8 Graham DY, Klein PD. Campylobacter pyloridis gastritis: the past, the present, and speculations about the future Am $\mathcal{F}$ Gastroenterol 1987; 82: 283-6.

9 Marshall BJ. Campylobacter pyloridis and gastritis. I Infect Dis 1986; 153: 650-7.

10 Lambert JR, Yeomans ND. Campylobacter pylori - gastroduodenal pathogen or opportunistic bystander? Aust $N Z \mathcal{Z} \mathrm{Med}$ 1988; 18: 555-6.

11 Piper DW. Bacteria, gastritis, acid hyposecretion and peptic ulcer. Med f A ust 1985; 142: 431.

12 Zuckerman GR, Mills BA, Koehler RE, Siegel A, Harter HR, DeSchryver-Kecskemeti $K$. Nodular duodenitis: pathologic and clinical characteristic in patients with end-stage renal and clinical characteristic in patients
disease. Dig Dis $S c i$ 1983; 28: 1018-24.

13 Paimela H, Harkonen M, Karonen SL, Tallgren LG, Stenman $S$, Ahonen J. Relationship between serum group II pepsinogen concentration and the degree of Brunner's gland hyperplasia in patients with chronic renal failure. Gut 1985 26: 198-202.

14 Mitchell CJ, Jewell DP, Lewin MR, McLaughlin JE Moorhead JF. Gastric function and histology in rena failure. J Clin Pathol 1979; 32: 208-13.

15 Garg AK, Gulat PD, Misra RC, Saha MM, Rizvi SNA Chauhan LC. Gastric functions in chronic uraemia and effects of dialysis. Ind f Gastroenterol 1984; 3: 73-5.

16 Vaziri ND, Dure-Smith B, Miller R, Mirahmadi MK. Pathology of gastrointestinal tract in chronic hemodialysis patients: an autopsy study of 78 cases. $A m \mathcal{f}$ Gastroenterol 1985; 80: 608-11.

17 McNulty CAM, Gearty JC, Crump B, et al. Campylobacter pyloridis and associated gastritis: investigator blind, placebo pyloridis and associated gastritis: investigator blind, placebo
controlled trial of bismuth salicylate and erythromycin controlled trial of bismuth salicylate and

18 Rathbone BJ, Wyatt JI, Heatley RV. Campylobacter pyloridis a new factor in peptic ulcer disease? Gut 1986; 27 : 635-41.

19 Varis K. Epidemiology of gastritis. Scand F Gastroenterol 1982 17 (suppl 79): 44-51.

20 Siurala M, Isokoski M, Varis K, Kekki M. Prevalence of gastritis in a rural population. Scand $\mathcal{F}$ Gastroenterol 1968; 3 : 211-23.

21 Villako K, Tamin A, Savisaar E, Ruttas M. Prevalence of antral and fundic gastritis in a randomly selected group of an Estonian rural population. Scand $\mathcal{F}$ Gastroenterol 1976; 11 : 817-22.

22 Morris A, Nicholson G, Lloyd G, et al. Seroepidemiology of Campylobacter pyloridis. N Z Med f 1986; 99: 657-9.

23 Ala-Kaila $\mathrm{K}$. Upper gastrointestinal findings in chronic renal failure. Scand f Gastroenterol 1987; 22: 372-6.

24 Milito G, Taccone-Gallucci M, Brancaleone C, et al. Assessment of the upper gastrointestinal tract in hemodialysis patients awaiting renal transplantation. Am $\mathcal{f}$ Gastroenterol patients awaiting

25 Tani N, Harasawa S, Suzuki S, et al. Lesions of the upper gastrointestinal tract in patients with chronic renal failure. Gastroenterol f pn 1980; 15: 480-4

26 Elta GH, Appelman HD, Behler EM, Wilson JAP, Nostrant TJ. A study of the correlation between endoscopic and histological diagnoses in gastroduodenitis. Am $\mathcal{F}$ Gastroenterol 1987; 82: 749-53.

27 Roesch W. Endoscopical and radiological findings in gastritis. Scand 7 Gastroenterol 1982; 17 (suppl 79): 53-7.

28 Shousha S, Spiller RC, Parkins RA. The endoscopically abnormal duodenum in patients with dyspepsia: biopsy findings in 60 cases. Histopathology 1983; 7: 23-4.

29 Paimela H, Tallgren LG, Stenman S, Numers HV, Scheinin TM. Multiple duodenal polyps in uraemia: a little known clinical entity. Gut 1984; 25: 256-63.

30 Franzin G, Musola R, Ghidini O, Manfrini C, Fratton A. Nodular hyperplasia of Brunner's glands. Gastrointest Endosc 1985; 31: 374-8. 